Jorge E. Cortes and Hagop M. Kantarjian The University of Texas MD Anderson Cancer Center, Houston, TX; Neil P. Shah, University of California San Francisco

School of Medicine, San Francisco, CA; Brigid Bradley-Garelik and George Manos, Bristol-Myers Squibb, Princeton, NJ; Giuseppe Saglio, University of Turin, Turin; Michele Baccarani, S. OrsolaMalpighi Hospital, University of Bologna, Bologna, Italy; Jirí Mayer, University Hospital Brno and Central European Institute of Technology, Masaryk University, Brno, Czech Republic; Concepción Boqué, Institut Català d'Oncologia, Hospital Duran i Reynals, L'Hospitalet, Barcelona, Spain; Charles Chuah, Singapore General Hospital, Duke-National University of Singapore Medical School, Singapore; Luis Casanova, Instituto Nacional de Enfermedades Neoplásicas, Lima, Perú; and Andreas Hochhaus,

Universitätsklinikum Jena, Jena, Germany.

Published online ahead of print at www.jco.org on May 23, 2016.

Supported by Bristol-Myers Squibb.

Presented in part at the 56th Annual Meeting of the American Society of Hematology, San Francisco, CA, December 6-9, 2014; the European

School of Haematology 16 th Annual John Goldman Conference on Chronic Myeloid Leukemia, Philadelphia, PA, September 4-7, 2014; and the annual meeting of the German, Austrian, and Swiss Societies of Haematology and Medical Oncology.

Basel, Switzerland, October 9-13, 2015.

Authors' disclosures of potential conflicts of interest are found in the article online at www.jco.org. Author contributions are found at the end of this article.

Corresponding author: Jorge E. Cortes, MD, Department of Leukemia, The University of Texas MD Anderson Cancer Center, 1515 Holcombe Blvd, Unit 0428, Houston, TX 77030; e-mail: jcortes@ mdanderson.org.

(c) 2016 by American Society of Clinical Oncology

0732-183X/16/3420w-2333w/\$20.00

DOI: 10.1200/JCO.2015.64.8899

\title{
Final 5-Year Study Results of DASISION: The Dasatinib Versus Imatinib Study in Treatment-Naïve Chronic Myeloid Leukemia Patients Trial
}

Jorge E. Cortes, Giuseppe Saglio, Hagop M. Kantarjian, Michele Baccarani, Jiři Mayer, Concepción Boqué, Neil P. Shah, Charles Chuah, Luis Casanova, Brigid Bradley-Garelik, George Manos, and Andreas Hochhaus

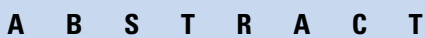

\section{Purpose}

We report the 5-year analysis from the phase III Dasatinib Versus Imatinib Study in Treatment-Naïve Chronic Myeloid Leukemia Patients (DASISION) trial, evaluating long-term efficacy and safety outcomes of patients with chronic myeloid leukemia (CML) in chronic phase (CP) treated with dasatinib or imatinib.

\section{Patients and Methods}

Patients with newly diagnosed CML-CP were randomly assigned to receive dasatinib 100 mg once daily ( $n=259$ ) or imatinib 400 mg once daily $(n=260)$.

\section{Results}

At the time of study closure, $61 \%$ and $63 \%$ of dasatinib- and imatinib-treated patients remained on initial therapy, respectively. Cumulative rates of major molecular response and molecular responses with a 4.0- or 4.5-log reduction in BCR-ABL 1 transcripts from baseline by 5 years remained statistically significantly higher for dasatinib compared with imatinib. Rates for progression-free and overall survival at 5 years remained high and similar across treatment arms. In patients who achieved $B C R-A B L 1$ $\leq 10 \%$ at 3 months (dasatinib, 84\%; imatinib, 64\%), improvements in progression-free and overall survival and lower rates of transformation to accelerated/blast phase were reported compared with patients with $B C R-A B L 1$ greater than $10 \%$ at 3 months. Transformation to accelerated/blast phase occurred in $5 \%$ and $7 \%$ of patients in the dasatinib and imatinib arms, respectively. Fifteen dasatinibtreated and 19 imatinib-treated patients had BCR-ABL 1 mutations identified at discontinuation. There were no new or unexpected adverse events identified in either treatment arm, and pleural effusion was the only drug-related, nonhematologic adverse event reported more frequently with dasatinib ( $28 \% v 0.8 \%$ with imatinib). First occurrences of pleural effusion were reported with dasatinib, with the highest incidence in year 1. Arterial ischemic events were uncommon in both treatment arms.

\section{Conclusion}

These final results from the DASISION trial continue to support dasatinib $100 \mathrm{mg}$ once daily as a safe and effective first-line therapy for the long-term treatment of CML-CP.

\section{J Clin Oncol 34:2333-2340. (C) 2016 by American Society of Clinical Oncology}

\section{INTRODUCTION}

The Dasatinib Versus Imatinib Study in TreatmentNaïve Chronic Myeloid Leukemia Patients (DASISION) study was a randomized phase III trial comparing the efficacy and safety of dasatinib with imatinib in patients with newly diagnosed chronic myeloid leukemia (CML) in chronic phase (CP). Initial results showed that dasatinib had met its primary end point of superior efficacy compared with imatinib and had an acceptable safety profile, leading to its approval for first-line use. ${ }^{1,2}$
In subsequent analyses, ${ }^{3-6}$ dasatinib continued to demonstrate deep and fast responses. Progression-free survival (PFS) and overall survival (OS) remained high and comparable between dasatinib and imatinib. Furthermore, the safety profile of dasatinib was consistent through each update.

Several studies with BCR-ABL1 tyrosine kinase inhibitors (TKIs) have reported that a deep, early response predicts improved outcomes in patients with CML-CP. ${ }^{5,7-18}$ The achievement of $B C R-A B L 1$ transcript levels of $\leq 10 \%$ according to the International Scale (IS) at 3 months has 
been associated with significantly improved PFS, event-free survival, and OS and a reduced risk of transformation. ${ }^{5,8,9,14}$

Here, we present the final, planned, 5-year analysis from DASISION. Long-term efficacy and safety outcomes, CML-related and -unrelated deaths, and $B C R-A B L 1$ mutation status are reported. Expected survival by age at diagnosis and response by Euro (Hasford) risk score are described.

\section{PATIENTS AND METHODS}

\section{Study Design and Treatment}

DASISION was a multinational, open-label, phase III trial (CA180056; ClinicalTrials.gov identifier: NCT00481247). Patients were stratified by Euro risk score ${ }^{19}$ and randomly assigned 1:1 to receive either oral dasatinib (100 mg once daily) or imatinib (400 mg once daily). Adverse events (AEs) were managed through treatment interruptions and dose reductions. Dose escalations to dasatinib $140 \mathrm{mg}$ once daily or imatinib 600 to $800 \mathrm{mg}$ once daily were permitted for suboptimal response at 3 to 18 months. ${ }^{20}$ The primary end point was confirmed complete cytogenetic response (cCCyR) rate by 12 months. Secondary end points were overall time to $\mathrm{CCCyR}$ and its duration, major molecular response (MMR) rate at any time, time to MMR overall, PFS, and OS.

\section{Patients}

Eligibility criteria and patient characteristics have been described, ${ }^{1}$ and key exclusion criteria are available in the Appendix (online only). Patients with uncontrolled or serious cardiovascular disease were not eligible, but those with common cardiovascular risk factors (uncontrolled hypertension or angina, congestive heart failure $>3$ months before enrollment, and myocardial infarction $>6$ months before enrollment) were eligible. The trial was approved by all institutional review boards and ethics committees. All patients gave written informed consent before random assignment in accordance with the Declaration of Helsinki.

\section{Evaluations}

Analyses after a minimum follow-up of 5 years are presented (database lock: March 24, 2014). Complete cytogenetic response (CCyR) was defined as $0 \%$ Philadelphia chromosome-positive cells in $\geq 20$ bone marrow metaphases. MMR and molecular responses $\mathrm{MR}^{4}$ and $\mathrm{MR}^{4.5}$ represent $B C R-A B L 1$ transcript levels of $\leq 0.1 \%, \leq 0.01 \%$, and $\leq 0.0032 \%$ (IS), corresponding to a $3-\log$, 4-log, and 4.5-log reduction from a standardized baseline, respectively. ${ }^{10,20,21}$ Missing samples and patients with atypical $B C R-A B L 1$ transcripts (not b2a2 or b3a2) were considered nonresponders. A central laboratory (MolecularMD, Portland, OR) performed molecular assessments. Treatment failure was defined as no hematologic response at 3 months, no complete hematologic response or no cytogenetic response at 6 months, no partial cytogenetic response at 12 months, no CCyR at 18 months, or progression at any time. ${ }^{20}$ Protocoldefined disease progression, on the basis of guidelines available during protocol design, ${ }^{20}$ included doubling of WBC count to greater than $20 \times$ $10^{9} / \mathrm{L}$, loss of complete hematologic response, increase in Philadelphia chromosome-positive bone marrow metaphases to $\geq 30 \%$ from nadir, transformation to accelerated/blast phase (AP/BP), or death from any cause. Transformation to CML-AP/BP did not include clonal evolution. ${ }^{20}$ Patients who agreed to follow-up ( $>98 \%$ in each arm) continued to be observed for transformation and survival for up to 5 years. Expected patient life spans by treatment were calculated by applying the OS rate as a percentage of the life span of the general population without CML. ${ }^{22}$ Poststudy CML treatment was to be captured for all patients. AEs were graded according to National Cancer Institute Common Terminology Criteria for Adverse Events version 3.0. ${ }^{23}$ Mutations were assessed at discontinuation of study treatment in patients with sufficient $B C R-A B L 1$ cDNA for amplification using Sanger direct sequencing (MolecularMD).

\section{Statistical Considerations}

Cumulative response rates were calculated using the cumulative incidence approach and Kaplan-Meier method. Comparisons of MR rates were performed using Cochran-Mantel-Haenszel testing methodology and stratified by Euro score. Unstratified comparison of rates by Euro score was performed using an exact test. Post hoc analyses compared response rates at various time points; therefore, $P$ values are descriptive and unadjusted for multiple comparisons. PFS and OS were estimated using Kaplan-Meier analysis. For PFS, patients who discontinued the study without progression were censored at the date of their last on-study hematologic or cytogenetic evaluation. Progression and transformation data after study discontinuation were obtained for patients who agreed to follow-up. For OS, patients were censored on the date they were last known to be alive. Hazard ratios (HRs) were based on the Cox model.

\section{RESULTS}

\section{Patient Disposition}

Of 519 patients enrolled onto DASISION, 259 were randomly assigned to receive dasatinib, and 260 were randomly assigned to receive imatinib (Fig 1), with well-balanced baseline characteristics in each arm. ${ }^{1}$ After 5 years, $61 \%$ of dasatinib-treated patients and $63 \%$ of imatinib-treated patients were still on initial therapy (Table 1 and Appendix Table A1, online only). The median average daily dose for treated patients was $99 \mathrm{mg}$ (range, 21 to $139 \mathrm{mg}$ ) for dasatinib and $400 \mathrm{mg}$ (range, 125 to $741 \mathrm{mg}$ ) for imatinib. Patients who discontinued the study as a result of study closure received $99 \mathrm{mg}$ (range, 56 to $139 \mathrm{mg}$ ) of dasatinib and $400 \mathrm{mg}$ (range, 287 to $741 \mathrm{mg}$ ) of imatinib, and patients who discontinued the study as a result of all other reasons received $95 \mathrm{mg}$ (range, 21 to $127 \mathrm{mg}$ ) of dasatinib and $400 \mathrm{mg}$ (range, 125 to $740 \mathrm{mg}$ ) of imatinib. After discontinuation, the most common subsequent treatments were imatinib (19\%), nilotinib (9\%), dasatinib (3\%), and hydroxyurea (2\%) for the dasatinib arm, and dasatinib (16\%), imatinib (11\%), nilotinib (9\%), and hydroxyurea (3\%) for the imatinib arm. All other poststudy CML treatments were reported for less than $2 \%$ of patients. Some patients continued the treatment received in DASISION after discontinuation from study drug.

\section{Efficacy}

Cumulative, 5-year MMR and $\mathrm{MR}^{4.5}$ rates were $76 \%$ and $42 \%$ for dasatinib and $64 \%$ and $33 \%$ for imatinib, respectively $(P=$ .0022 and $P=.0251$, respectively; Fig 2). Proportions of randomly assigned patients with responses at 5 years in the dasatinib and imatinib arms were $28 \%$ and $26 \%$ for cCCyR, $52 \%$ and $49 \%$ for MMR, $39 \%$ and $28 \%$ for $\mathrm{MR}^{4}$, and $25 \%$ and $18 \%$ for $\mathrm{MR}^{4.5}$, respectively. At study end, patients were not required to provide samples for bone marrow cytogenetics, possibly leading to lower values for CCCyR in both arms. The achievement of MMR and $\mathrm{MR}^{4.5}$ at any time by Euro score was also investigated (Appendix Fig A1, online only). Significant differences between dasatinib- and imatinib-treated patients were observed for MMR in the low-risk group $(P<.001)$ and for $\mathrm{MR}^{4.5}$ in the intermediate-risk group $(P=.0218)$. 


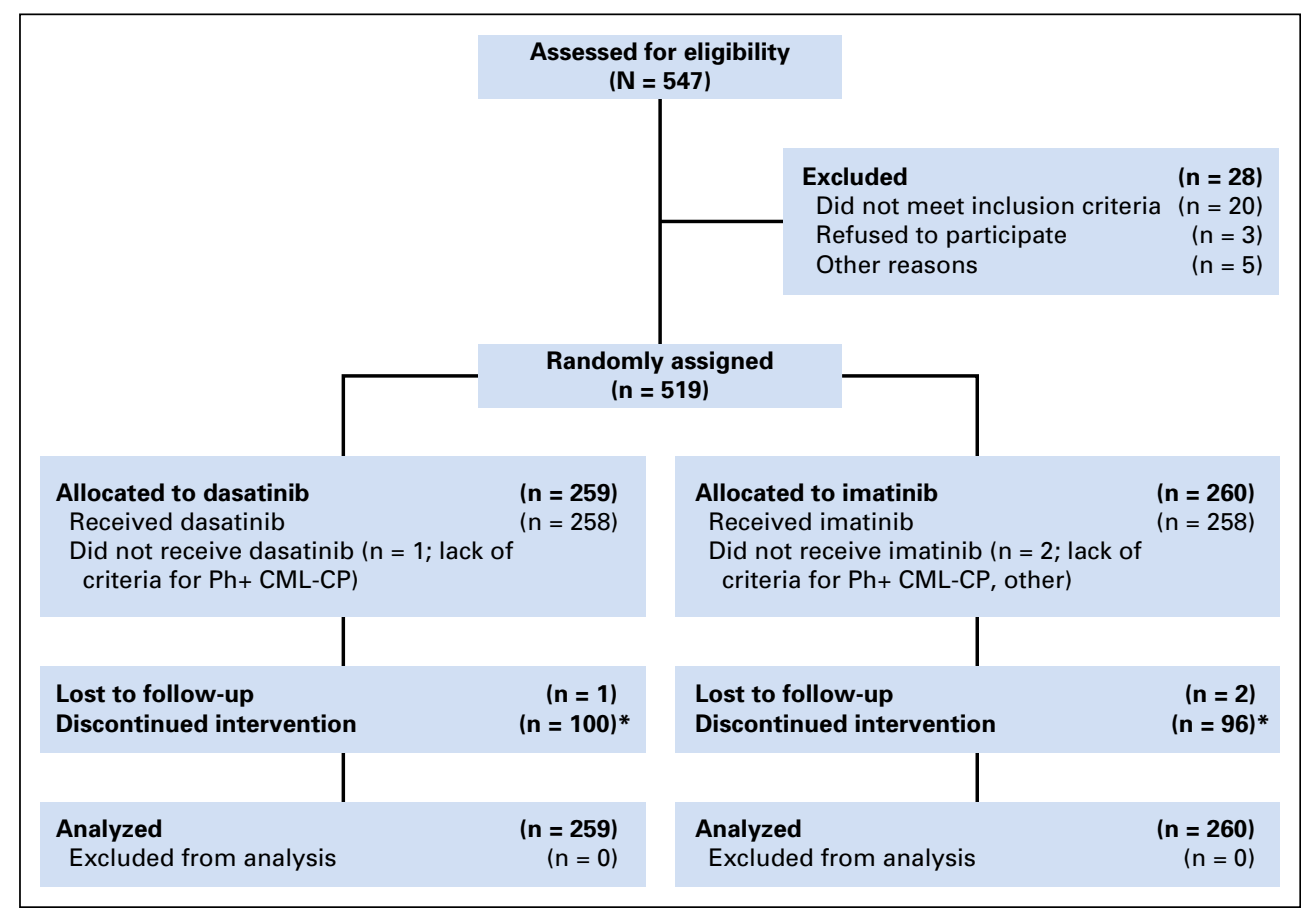

Fig 1. CONSORT diagram for the DASISION trial after a minimum follow-up of 5 years. CML-CP, chronic myeloid leukemia in chronic phase; $\mathrm{Ph}+$, Philadelphia chromosome positive. $\left(^{*}\right)$ Reasons for discontinuation are listed in Table 1.

Estimated 5-year OS was 91\% for dasatinib and 90\% for imatinib (HR, 1.01; 95\% CI, 0.58 to 1.73; Appendix Fig A2, online only). In the analysis of expected life span by age at diagnosis, the age-adjusted life expectancy for patients with CML-CP in both arms of DASISION approached that for patients from an external, non-CML population ${ }^{22}$ (Appendix Fig A3, online only). More imatinib-treated patients died as a result of CML-related causes $(n=17)$ compared with dasatinibtreated patients $(n=9)$; however, the related 5-year OS was not statistically significantly different ( $P=.1192 ; \mathrm{HR}, 0.53 ; 95 \% \mathrm{CI}, 0.24$ to 1.19 ).

Estimated 5-year PFS was $85 \%$ for dasatinib and $86 \%$ for imatinib (HR, 1.06; 95\% CI, 0.68 to 1.66; Appendix Fig A2).
Including follow-up beyond on-study treatment discontinuation (intent to treat), $4.6 \%$ and $7.3 \%$ of patients on dasatinib and imatinib, respectively, transformed to AP/BP by 5 years. Two patients in the imatinib group and none in the dasatinib group transformed between 3 and 5 years.

As reported previously, a higher percentage of dasatinibtreated patients achieved $B C R-A B L 1 \leq 10 \%$ (IS) at 3 months compared with imatinib-treated patients $(84 \%$ and $64 \%$, respectively). ${ }^{5}$ The proportions of dasatinib-treated patients age 65 and younger and older than 65 years who achieved $B C R-A B L 1 \leq$ $10 \%$ (IS) at 3 months were similar, as were the proportions of

\begin{tabular}{|c|c|c|}
\hline \multirow[b]{2}{*}{ Status } & \multicolumn{2}{|c|}{ No. of Patients (\%) } \\
\hline & $\begin{array}{l}\text { Dasatinib } 100 \mathrm{mg} \text { Once Daily } \\
\qquad(\mathrm{n}=258)\end{array}$ & $\begin{array}{l}\text { Imatinib } 400 \mathrm{mg} \text { Once Daily } \\
\qquad(\mathrm{n}=258)\end{array}$ \\
\hline On initial therapy at study end & $158(61)$ & $162(63)$ \\
\hline \multicolumn{3}{|l|}{ Discontinued } \\
\hline Progression or treatment failure & $28(11)$ & $36(14)$ \\
\hline Intolerance* & $42(16)$ & $17(7)$ \\
\hline AE unrelated to study treatment & $12(5)$ & $4(2)$ \\
\hline Poor compliance/nonadherence & $1(<1)$ & $7(3)$ \\
\hline Patient request & $4(2)$ & $10(4)$ \\
\hline Withdrawal of consent & $4(2)$ & $3(1)$ \\
\hline Lost to follow-up & $1(<1)$ & $2(1)$ \\
\hline Other & $8(3) \dagger$ & $16(6) \ddagger$ \\
\hline \multicolumn{3}{|c|}{$\begin{array}{l}\text { Abbreviation: } A E \text {, adverse event. } \\
{ }^{*} \text { As decided by investigator. Intolerance is defined as recurrent grade } \geq 3 \text { hematologic toxicity or grade } \geq 2 \text { nonhematologic toxicity requiring discontinuation despite } \\
\text { dose reduction. } \\
\text { Hncludes insufficient molecular response }(n=3) \text {, pregnancy }(n=2) \text {, loss of complete cytogenetic response }(n=1) \text {, increased } B C R-A B L 1(n=1) \text {, and relocation to the } \\
\text { United States }(n=1) \text {. } \\
\text { fIncludes no molecular response/loss of molecular response }(n=4) \text {, suboptimal response }(n=3) \text {, insufficient cytogenetic response }(n=2) \text {, investigator request }(n=2) \text {, } \\
\text { pregnancy }(n=1) \text {, recurrence of blasts in bone marrow }(n=1) \text {, no complete molecular response }(n=1) \text {, no major molecular response }(n=1) \text {, and appearance of mutation } \\
(n=1) \text {. }\end{array}$} \\
\hline
\end{tabular}




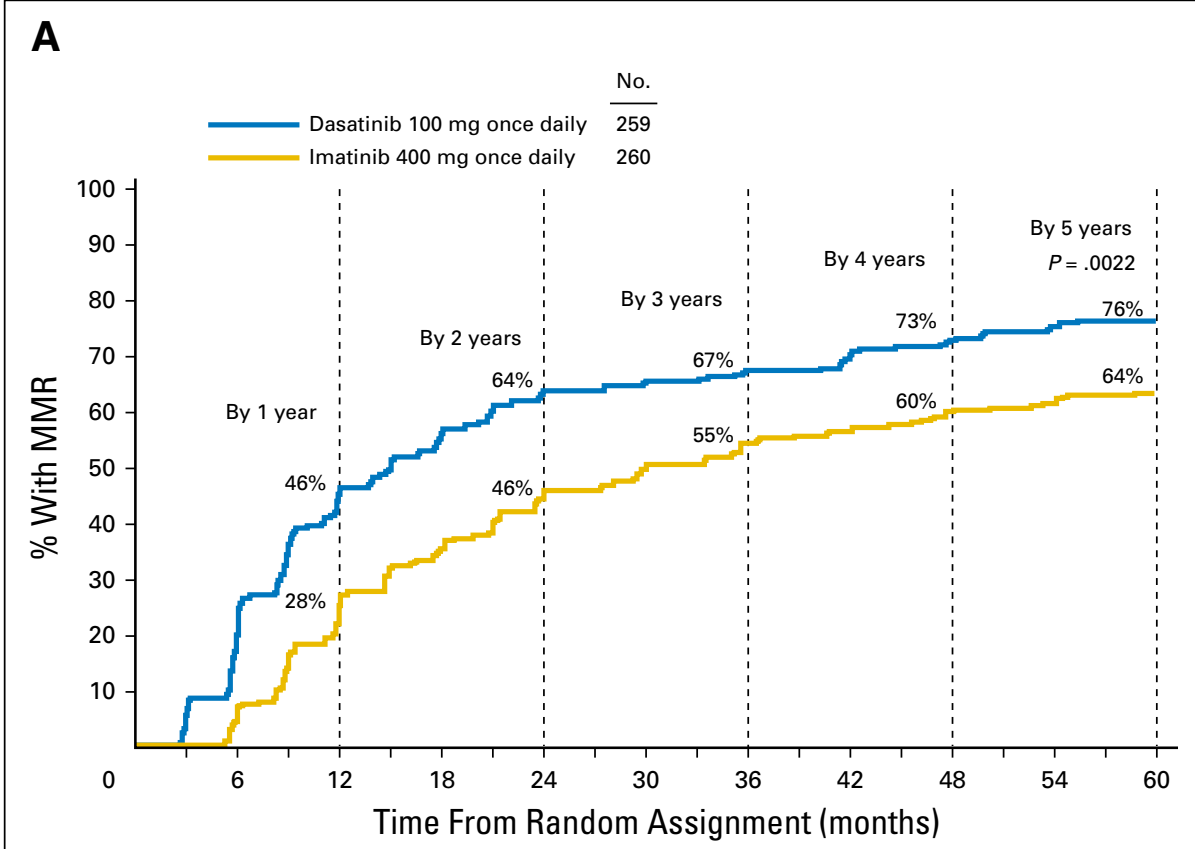

B

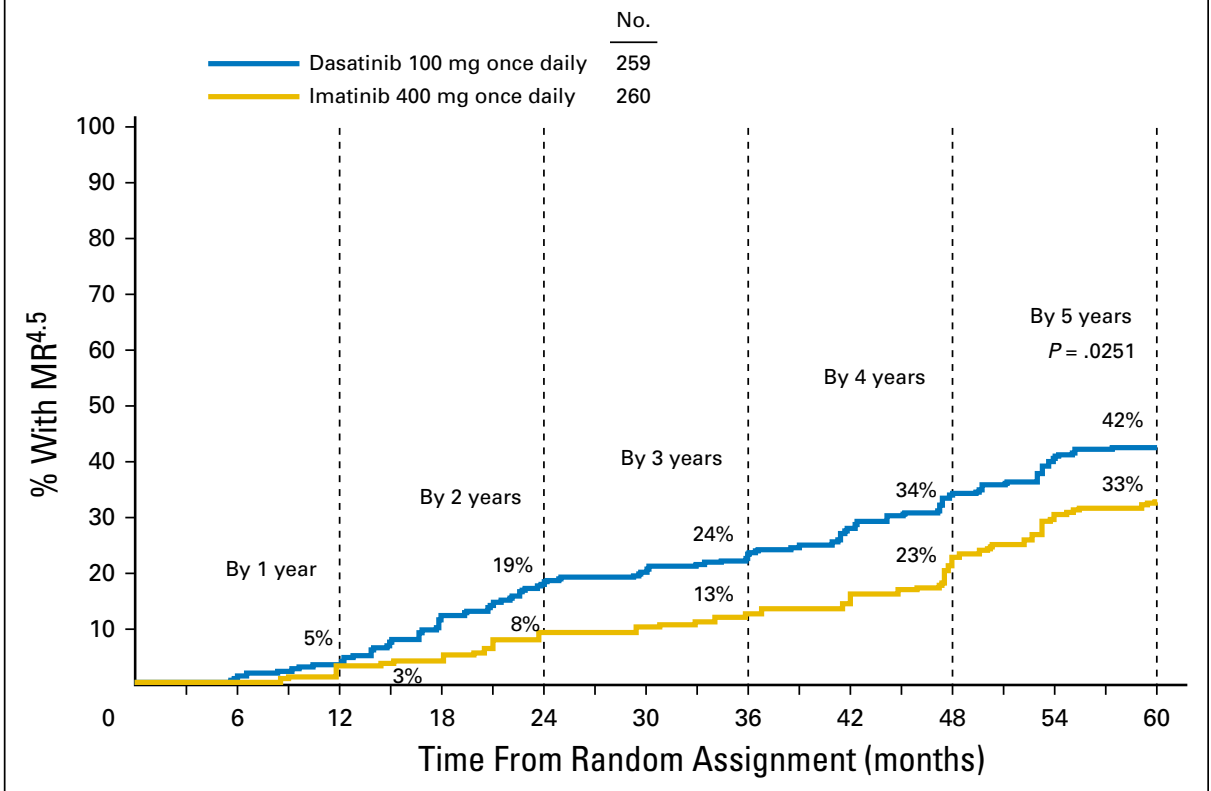

Fig 2. Cumulative response rates over time. The percentages of patients with $(A)$ major molecular response $(M M R)$ and $(B)$ molecular response with a 4.5-log reduction in $B C R-A B L 1$ transcripts from baseline (MR ${ }^{4.5} ; B C R-A B L 1$ transcript level $\leq$ $0.0032 \%$ [International Scale]) by $1,2,3,4$, and 5 years are shown. imatinib-treated patients age 65 and younger and older than 65 years. In both arms, patients who achieved $B C R-A B L 1 \leq 10 \%$ (IS) at 3 months more often reached CCyR, MMR, and $\mathrm{MR}^{4.5}$ by 5 years (Table 2), had higher rates of OS and PFS (Fig 3), and had a lower transformation rate $(3 \% \vee 14 \%$ to $15 \%$ in patients who did not achieve $B C R-A B L 1 \leq 10 \%$ at 3 months).

\section{Mutational Analysis}

Testing for $B C R-A B L 1$ mutations was planned in all patients at treatment or study discontinuation (Appendix Table A2, online only). Of the available samples, 200 patients (81\%) in the dasatinib arm and 214 patients $(83 \%)$ in the imatinib arm had mutation analysis performed. Mutations were identified in 15 (8\%) of 200 patients and $19(9 \%)$ of 214 patients in the dasatinib and imatinib arms, respectively. T315I mutations were identified in eight dasatinib-treated patients and no imatinib-treated patients. Most patients who had mutations discontinued treatment as a result of progression or treatment failure (dasatinib, $\mathrm{n}=13$ of 15 patients; imatinib, $\mathrm{n}=14$ of 19 patients).

\section{Safety}

No new AEs were observed with dasatinib or imatinib by 5 years. Overall, most AEs reported with both drugs were grade 1 or $2 ; 15 \%$ of AEs reported with dasatinib and $11 \%$ of AEs reported 


\begin{tabular}{|c|c|c|c|c|}
\hline \multirow[b]{3}{*}{ Response } & \multicolumn{4}{|c|}{$\%$ of Patients } \\
\hline & \multicolumn{2}{|c|}{$\begin{array}{l}\text { Dasatinib } 100 \mathrm{mg} \text { Once Daily } \\
\qquad(\mathrm{n}=259)\end{array}$} & \multicolumn{2}{|c|}{$\begin{array}{l}\text { Imatinib } 400 \mathrm{mg} \text { Once Daily } \\
\qquad(\mathrm{n}=260)\end{array}$} \\
\hline & $\begin{array}{c}\text { 3-Month } B C R-A B L 1 \text { Transcript } \\
\text { Level } \leq 10 \% \\
(n=198 ; 84 \%)\end{array}$ & $\begin{array}{c}\text { 3-Month } B C R-A B L 1 \text { Transcript } \\
\text { Level }>10 \% \\
(\mathrm{n}=37 ; 16 \%)\end{array}$ & $\begin{array}{c}\text { 3-Month } B C R-A B L 1 \text { Transcript } \\
\text { Level } \leq 10 \% \\
(n=154 ; 64 \%)\end{array}$ & $\begin{array}{c}\text { 3-Month } B C R-A B L 1 \text { Transcript } \\
\text { Level }>10 \% \\
(n=85 ; 36 \%)\end{array}$ \\
\hline $\begin{array}{l}\text { Complete cytogenetic } \\
\text { response }\end{array}$ & 94 & 41 & 92 & 59 \\
\hline $\begin{array}{l}\text { Major molecular } \\
\text { response }\end{array}$ & 87 & 38 & 81 & 41 \\
\hline $\mathrm{MR}^{4.5}$ & 54 & 5 & 48 & 12 \\
\hline
\end{tabular}

with imatinib were grade 3 or 4 . Rates of grade 3 or 4 hematologic AEs were higher for dasatinib versus imatinib (neutropenia, 29\% $v$ 24\%; anemia, 13\% v 9\%; and thrombocytopenia, 22\% v 14\%, respectively). Except for pleural effusion, drug-related, nonhematologic AEs were reported less frequently with dasatinib than imatinib or were comparable (Fig 4). Drug-related AEs were

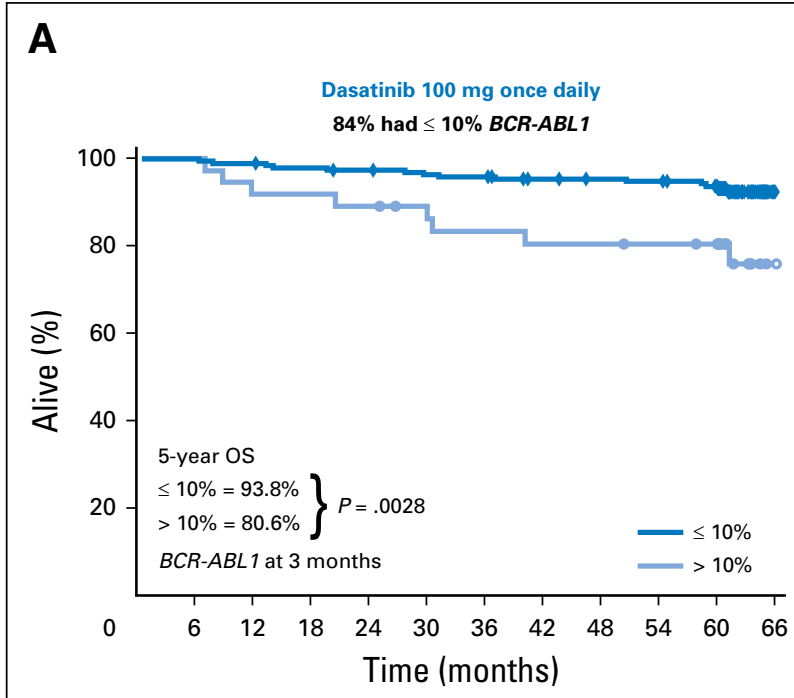

B

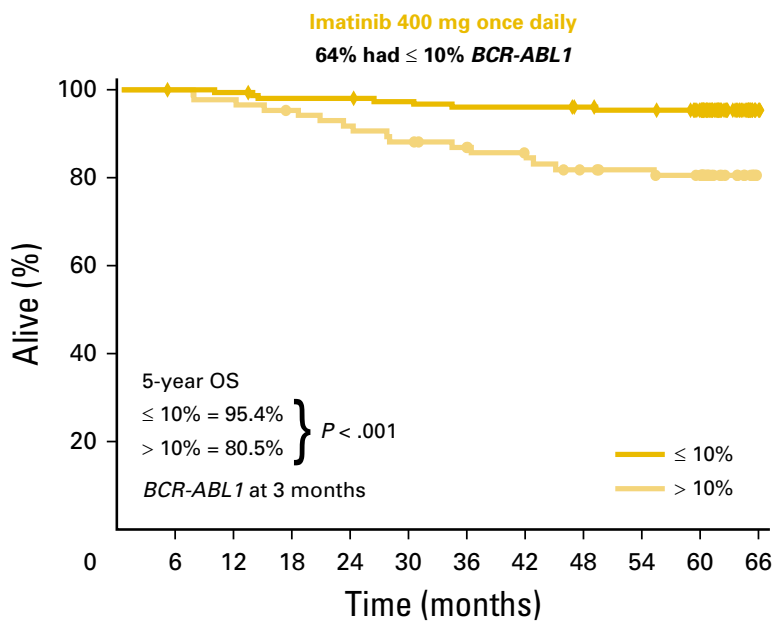

C

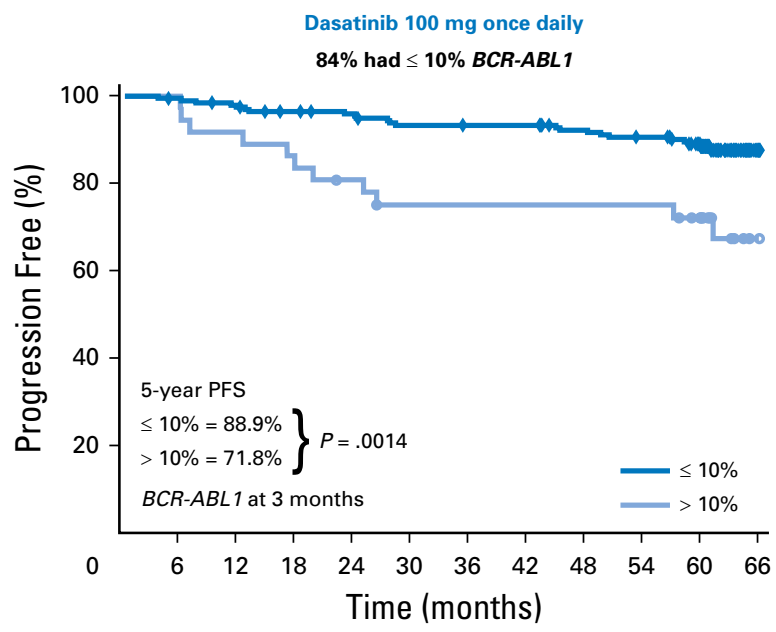

D

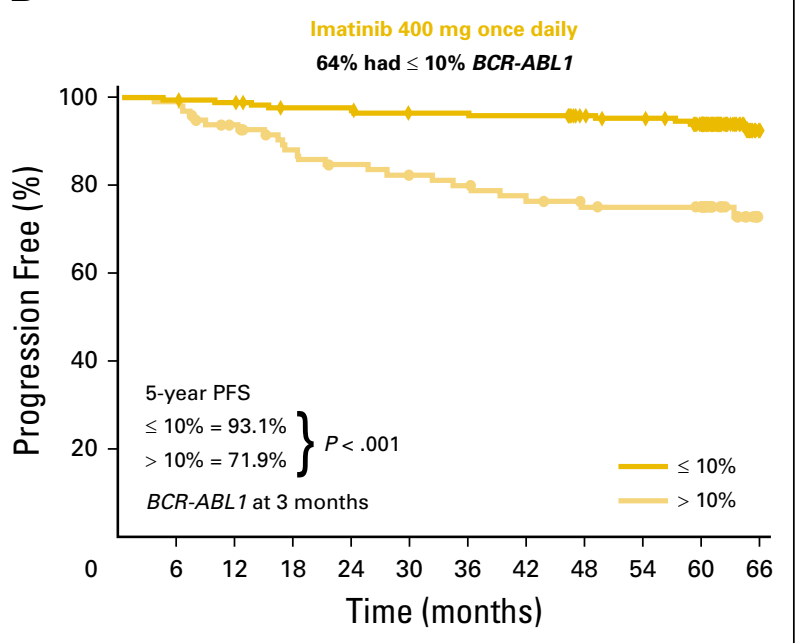

Fig 3. Estimated 5 -year ( $A, B$ ) overall survival (OS) and (C, D) progression-free survival (PFS) by molecular response at 3 months for both treatment arms. OS and PFS were calculated using patients on study treatment and in follow-up after discontinuation of randomly assigned treatment. 
manageable, leading to discontinuation in $16 \%$ and $7 \%$ of patients in the dasatinib and imatinib arms, respectively.

Drug-related pleural effusion was more common with dasatinib $(28 \%)$ than with imatinib $(0.8 \%)$. Sixty-six patients (26\%) experienced grade 1 or 2 , seven patients (3\%) experienced grade 3 or 4 , and no patients experienced grade 5 pleural effusion on dasatinib. Pleural effusion developed in approximately $8 \%$ of at-risk dasatinib-treated patients in year 1 of therapy and was comparable each subsequent year (Appendix Table A3, online only). The percentage of patients who developed pleural effusions was higher in patients age $\geq 65$ years ( 15 of 25 patients; $60 \%$ ) compared with patients younger than age 65 years (58 of 233 patients; 25\%). Drug-related pleural effusion was managed with dose interruption (62\%) and/or dose reduction $(41 \%)$, diuretics $(47 \%)$, corticosteroids $(32 \%)$, or therapeutic thoracocentesis (12\%). Only 15 patients $(6 \%)$ discontinued dasatinib and only one patient discontinued imatinib as a result of pleural effusion. Pleural effusion did not impair the ability of patients to obtain a response; 71 patients (96\%) achieved a cCCyR, 61 (82\%) achieved an MMR, and 37 (50\%) achieved an $\mathrm{MR}^{4.5}$.

Pulmonary hypertension ( $\mathrm{PH})$, which was diagnosed with two-dimensional echocardiography, was reported in 14 dasatinibtreated patients $(5 \%)$ and one imatinib-treated patient $(0.4 \%)$. Of the $14 \mathrm{PH}$ diagnoses in dasatinib-treated patients, nine patients had pleural effusion. Right heart catheterization is recommended by the WHO to confirm moderate to severe precapillary $\mathrm{PH}$ and establish a diagnosis of pulmonary arterial hypertension (PAH) ${ }^{24}$ However, only one dasatinib-treated patient with $\mathrm{PH}$ had this procedure performed, and it did not support a diagnosis of PAH. The remaining 13 patients with a $\mathrm{PH}$ diagnosis were not evaluated according to these criteria. Of the $14 \mathrm{PH}$ diagnoses, 12 were drug related.

Because arterial ischemic events have been described during TKI therapy for CML, ${ }^{25}$ cardiovascular, cerebrovascular, and peripheral vascular events were evaluated. Arterial ischemic events were uncommon in both the dasatinib (5\%) and imatinib (2\%) treatment arms (Appendix Table A4, online only). Seven of 10 cardiovascular ischemic events occurred within year 1 of dasatinib therapy; most patients restarted dasatinib without a recurrent event. Additionally, two dasatinib-treated patients (imatinib, $\mathrm{n}=0$ ) had a transient ischemic attack, and two imatinib-treated patients (dasatinib, $\mathrm{n}=0$ ) had peripheral arterial disease. No patients experienced a stroke.

Twenty-six patients (10\%) died in each arm by 5 years, a fraction within 30 days of their last treatment (eight patients [3\%] in the dasatinib arm and five patients [2\%] in the imatinib arm). Four deaths, three in dasatinib-treated patients and one in imatinib-treated patients, were reported after the start of subsequent CML therapy ( $\mathrm{n}=3$ on nilotinib; $\mathrm{n}=1$ on nilotinib and imatinib after dasatinib discontinuation). Overall, causes of death included cardiovascular disease (dasatinib, $\mathrm{n}=2$; imatinib, $\mathrm{n}=1$ ); disease progression (dasatinib, $\mathrm{n}=9$; imatinib, $\mathrm{n}=17$ ); infection (dasatinib, $\mathrm{n}=11$; imatinib, $\mathrm{n}=1$ ); other malignancy, septic shock and cardiac failure, multiorgan failure, and whole-body swelling (dasatinib, $\mathrm{n}=1$ each); stem-cell transplantation complications and unknown cause (imatinib, $\mathrm{n}=2$ each); and severe chest pain, clinical deterioration and decrease in performance status, and fatal bleeding (imatinib, $\mathrm{n}=1$ each). Four of 11 dasatinib-treated patients who died of infection died within 30 days of their last dose (Klebsiella meningoencephalitis, sepsis, pneumonia, and unknown cause). The remaining seven patients died of various forms of infection (encephalitis, aspiration pneumonia, pulmonary infection, jaundice/malarial fever, sepsis, septic shock, and unknown cause) between 69 days and 4.5 years after their last dose, with two patients having transformed to AP/ $\mathrm{BP}$ before death. Only one patient who died as a result of infection had neutropenia, and this patient discontinued dasatinib more than 4 years before death.

\section{DISCUSSION}

The final study results from DASISION confirm that dasatinibtreated patients have high MR rates and that the achievement of $B C R-A B L 1 \leq 10 \%$ (IS) at 3 months is predictive of significantly higher PFS and OS rates. The dasatinib arm had more patients achieve $B C R-A B L 1 \leq 10 \%$ (IS) at 3 months and fewer CML-related deaths (nine of 26 patients $v 17$ of 26 patients in dasatinib and imatinib arms, respectively). The benefit of dasatinib has been

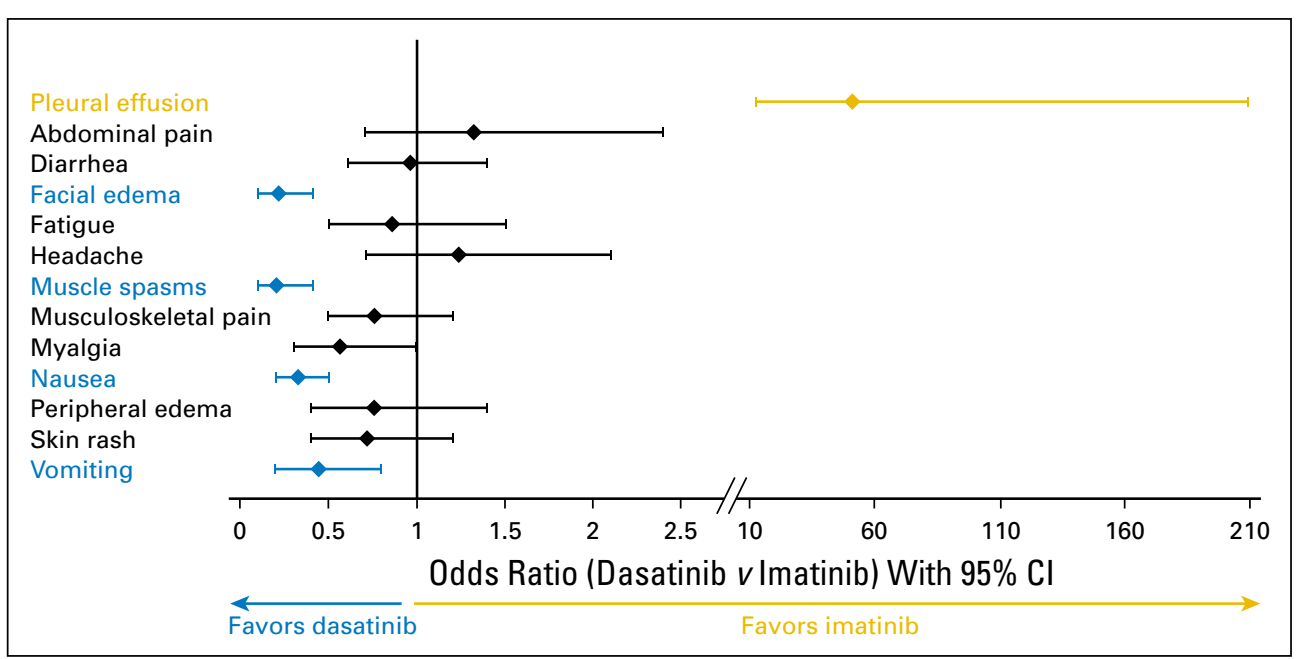

Fig 4. Drug-related, nonhematologic adverse events (AEs) reported in $\geq 10 \%$ of patients. Odds ratios (dasatinib $v$ imatinib) with $95 \% \mathrm{Cls}$ are shown for AEs that occurred in $\geq 10 \%$ of patients. Blue favors dasatinib, and gold favors imatinib. 
confirmed in additional randomized trials, ${ }^{26-28}$ making the data supporting the overall benefit with dasatinib robust.

PFS and OS rates remain high and comparable between the two treatment arms, with more dasatinib patients achieving early treatment milestones. Patients with CML are now living almost as long as the general population. ${ }^{29}$ Therefore, given high OS rates (approximately $90 \%$ at 5 years) and a majority of patients achieving CCyR, a larger population over a longer period of time may demonstrate a statistically significant survival difference. Another possible explanation for indistinguishable survival benefit is that $26 \%$ of patients were treated with the secondgeneration TKIs dasatinib $(16 \%)$ or nilotinib (9\%) after discontinuation of imatinib, which can rescue patients with imatinib failure.

Notably, in an intent-to-treat analysis, a disproportionate number of dasatinib-treated patients $(\mathrm{n}=11)$ died as a result of infection compared with imatinib-treated patients $(n=1)$. Most infection deaths ( $\mathrm{n}=7$ of 11 deaths) occurred between 69 days and 4.5 years after dasatinib was discontinued, including five patients who were receiving nilotinib or imatinib at the time of infection. Prior studies with dasatinib as initial therapy for CML have not reported a significant increase in risk of infections. ${ }^{27,28,30,31}$ However, follow-up for these studies at the time of this report was either short or included only preliminary results. It will be important to prospectively and intentionally look at a possible imbalance in the occurrence of infections and, if present, determine a possible mechanism(s) for dasatinib-related infectious complications.

Few patients in either arm developed $B C R-A B L 1$ mutations. Different numbers of patients with mutations were identified here and in the 3-year mutational analysis of DASISION. Mutations assessed in the 3-year report were from a more diverse patient population, those with an on-treatment event (no cCCyR and no MMR within 12 months, five-fold increase in $B C R-A B L 1$ with loss of MMR, or loss of CCyR). ${ }^{32}$ Here, T315I mutations were identified with dasatinib $(\mathrm{n}=8)$ but not imatinib. Previous reports have demonstrated a $2 \%$ rate of T315I mutations after a median of 31 months on imatinib, ${ }^{33}$ making the absence of this mutation in DASISION unexpected. One possible explanation for the disparity in T315I mutations between the two study arms is the decreased diversity in mutations that are resistant to dasatinib versus those that are resistant to imatinib, resulting in fewer mutants to dominate resistance mechanisms. It has been suggested that some mutations (ie, Y253H/F, E255K) may confer higher transformation potency in vitro than others (ie, T315I). ${ }^{32}$ If true, one could speculate that the more proliferative clones would emerge. However, if these were suppressed by dasatinib, less proliferative, unsuppressed clones would predominate. Further studies are required to investigate this hypothesis. Most patients with mutations discontinued treatment because of progression or treatment failure, consistent with the 3 -year analysis. ${ }^{32}$

The safety profile for dasatinib remains consistent, with no new safety signals identified after 5 years. Other than pleural effusion, the most common drug-related nonhematologic AEs were either similar between dasatinib and imatinib or lower with dasatinib. Pleural effusion was more common with dasatinib, occurred throughout this trial, and led to discontinuation in $6 \%$ of patients. Almost all patients (96\%) with pleural effusion achieved cCCyR, and $82 \%$ achieved MMR. These results suggest that, with adequate management, patients with pleural effusion may be able to remain on dasatinib. Serious, but rare, AEs have been reported with use of TKIs in CML, including hepatotoxicity ${ }^{34}$ and renal dysfunction with imatinib, ${ }^{35} \mathrm{PAH}$ with dasatinib, ${ }^{24,36}$ cardiac and vascular events with nilotinib, ${ }^{37}$ and arterial and venous thrombosis and occlusions with ponatinib. ${ }^{38}$ Some dasatinib-treated patients experienced $\mathrm{PH}$. There were no reports of $\mathrm{PAH}$ fitting the criteria defined by $\mathrm{WHO}$, which require right heart catheterization, although this procedure was only attempted in one patient, making the evaluation of true $\mathrm{PAH}$ incidence in this report inaccurate. As previously reported, ${ }^{39}$ there may be an association between $\mathrm{PH}$ and pleural effusion because nine of 14 patients with $\mathrm{PH}$ also had pleural effusion. Awareness and investigation of $\mathrm{PH}$ are important aspects of proper management of dasatinib-treated patients.

Arterial ischemic events were not common in either treatment arm. No dasatinib-treated patients experienced peripheral arterial disease. Rates of cardiovascular ischemic events on dasatinib (4\%) and imatinib $(2 \%)$ were similar to those reported in the general population. ${ }^{40,41}$ Nonetheless, physicians should be aware of these cardiovascular ischemic events, effectively manage comorbidities, and identify these events promptly.

AEs have been reported to increase nonadherence to TKIs. ${ }^{42,43}$ The proportion of patients in DASISION who discontinued dasatinib or imatinib as a result of poor compliance or noncompliance was small. It is currently unclear whether patients treated in community practices would have similarly low levels of noncompliance to TKIs outside of a clinical trial. Given that noncompliance has been shown to negatively affect treatment responses and outcomes, ${ }^{43-46}$ it is an important question to address in future studies to support successful treatment of CML.

In summary, the final, long-term results from DASISION demonstrated that patients taking dasatinib had faster and deeper MRs than patients taking imatinib. However, at the time of this final report, PFS and OS rates were similar for both cohorts. There were no new safety signals observed with dasatinib through 5 years or with longer follow-up. These results suggest that first-line dasatinib should continue to be considered a standard first-line therapy for patients with newly diagnosed CML-CP.

\section{AUTHORS' DISCLOSURES OF POTENTIAL CONFLICTS} OF INTEREST

Disclosures provided by the authors are available with this article at www.jco.org.

\section{AUTHOR CONTRIBUTIONS}

Conception and design: All authors

Provision of study materials or patients: All authors

Collection and assembly of data: All authors

Data analysis and interpretation: All authors

Manuscript writing: All authors

Final approval of manuscript: All authors 


\section{REFERENCES}

1. Kantarjian $H$, Shah $N P$, Hochhaus $A$, et al: Dasatinib versus imatinib in newly diagnosed chronic-phase chronic myeloid leukemia. N Engl J Med 362:2260-2270, 2010

2. Bristol-Myers Squibb: Sprycel (dasatinib) [prescribing information]. Princeton, NJ, BristolMyers Squibb Company, 2015

3. Cortes JE, Hochhaus A, Kim DW, et al: Fouryear (yr) follow-up of patients (pts) with newly diagnosed chronic myeloid leukemia in chronic phase (CML-CP) receiving dasatinib or imatinib: Efficacy based on early response. Blood 122:653, 2013 (abstr)

4. Hochhaus $\mathrm{A}$, Kantarjian $\mathrm{H}$ : The development of dasatinib as a treatment for chronic myeloid leukemia (CML): From initial studies to application in newly diagnosed patients. J Cancer Res Clin Oncol 139:1971-1984, 2013

5. Jabbour E, Kantarjian HM, Saglio G, et al: Early response with dasatinib or imatinib in chronic myeloid leukemia: 3-year follow-up from a randomized phase 3 trial (DASISION). Blood 123:494-500, 2014

6. Kantarjian HM, Shah NP, Cortes JE, et al: Dasatinib or imatinib in newly diagnosed chronicphase chronic myeloid leukemia: 2-year follow-up from a randomized phase 3 trial (DASISION). Blood 119:1123-1129, 2012

7. Alvarado $Y$, Kantarjian $H, O^{\prime} B r i e n ~ S$, et al: Significance of suboptimal response to imatinib, as defined by the European LeukemiaNet, in the long-term outcome of patients with early chronic myeloid leukemia in chronic phase. Cancer 115:3709-3718, 2009

8. Branford S, Kim DW, Soverini $S$, et al: Initial molecular response at 3 months may predict both response and event-free survival at 24 months in imatinib-resistant or -intolerant patients with Philadelphia chromosome-positive chronic myeloid leukemia in chronic phase treated with nilotinib. J Clin Oncol 30:4323-4329, 2012

9. Hanfstein $B$, Müller MC, Hehlmann R, et al: Early molecular and cytogenetic response is predictive for long-term progression-free and overall survival in chronic myeloid leukemia (CML). Leukemia 26:2096-2102, 2012

10. Hughes TP, Hochhaus A, Branford $S$, et al: Long-term prognostic significance of early molecular response to imatinib in newly diagnosed chronic myeloid leukemia: An analysis from the International Randomized Study of Interferon and STI571 (IRIS). Blood 116:3758-3765, 2010

11. Hughes TP, Kaeda J, Branford S, et al: Frequency of major molecular responses to imatinib or interferon alfa plus cytarabine in newly diagnosed chronic myeloid leukemia. N Engl J Med 349:1423-1432, 2003

12. Jabbour $E$, Kantarjian $H M$, O'Brien $S$, et al: Front-line therapy with second-generation tyrosine kinase inhibitors in patients with early chronic phase chronic myeloid leukemia: What is the optimal response? J Clin Oncol 29:4260-4265, 2011

13. Marin $D$, Hedgley $C$, Clark RE, et al: Predictive value of early molecular response in patients with chronic myeloid leukemia treated with first-line dasatinib. Blood 120:291-294, 2012

14. Marin $D$, Ibrahim AR, Lucas $C$, et al: Assessment of BCR-ABL1 transcript levels at 3 months is the only requirement for predicting outcome for patients with chronic myeloid leukemia treated with tyrosine kinase inhibitors. J Clin Oncol 30:232-238, 2012
15. Marin D, Milojkovic D, Olavarria E, et al: European LeukemiaNet criteria for failure or suboptimal response reliably identify patients with $\mathrm{CML}$ in early chronic phase treated with imatinib whose eventual outcome is poor. Blood 112:4437-4444, 2008

16. Neelakantan $P$, Gerrard G, Lucas $C$, et al: Combining BCR-ABL1 transcript levels at 3 and 6 months in chronic myeloid leukemia: Implications for early intervention strategies. Blood 121:2739-2742, 2013

17. Quintás-Cardama $A$, Kantarjian $H$, Jones $D$, et al: Delayed achievement of cytogenetic and molecular re sponse is associated with increased risk of progression among patients with chronic myeloid leukemia in early chronic phase receiving high-dose or standard-dose imatinib therapy. Blood 113:6315-6321, 2009

18. Wang $L$, Pearson $K$, Ferguson JE, et al: The early molecular response to imatinib predicts cytogenetic and clinical outcome in chronic myeloid leukaemia. Br J Haematol 120:990-999, 2003

19. Hasford J, Pfirrmann M, Hehlmann R, et al: A new prognostic score for survival of patients with chronic myeloid leukemia treated with interferon alfa. J Natl Cancer Inst 90:850-858, 1998

20. Baccarani M, Saglio G, Goldman J, et al: Evolving concepts in the management of chronic myeloid leukemia: Recommendations from an exper panel on behalf of the European LeukemiaNet. Blood 108:1809-1820, 2006

21. Hughes $T$, Deininger $M$, Hochhaus $A$, et al: Monitoring $\mathrm{CML}$ patients responding to treatment with tyrosine kinase inhibitors: Review and recommendations for harmonizing current methodology for detecting BCR$A B L$ transcripts and kinase domain mutations and for expressing results. Blood 108:28-37, 2006

22. Ludwig H, Bolejack V, Crowley J, et al: Survival and years of life lost in different age cohorts of patients with multiple myeloma. J Clin Oncol 28: 1599-1605, 2010

23. National Cancer Institute: Common Terminology Criteria for Adverse Events v3.0, August 2006. http://ctep.cancer.gov/protocolDevelopment/ electronic_applications/docs/ctcaev3.pdf

24. Simonneau G, Gatzoulis MA, Adatia I, et al: Updated clinical classification of pulmonary hyper tension. J Am Coll Cardiol 62:D34-D41, 2013 (suppl)

25. Valent $P$, Hadzijusufovic $E$, Schernthaner $G H$, et al: Vascular safety issues in $\mathrm{CML}$ patients treated with BCR/ABL1 kinase inhibitors. Blood 125: 901-906, 2015

26. Hjorth-Hansen $H$, Stenke $L$, Söderlund $S$, et al: Dasatinib induces fast and deep responses in newly diagnosed chronic myeloid leukaemia patients in chronic phase: Clinical results from a randomised phase-2 study (NordCML006). Eur J Haematol 94: 243-250, 2015

27. O'Brien SG, Hedgley C, Adams S, et al: Spirit 2: An NCRI randomised study comparing dasatinib with imatinib in patients with newly diagnosed CML. Blood 124:517, 2014 (abstr)

28. Radich JP, Kopecky KJ, Appelbaum FR, et al: A randomized trial of dasatinib $100 \mathrm{mg}$ versus imatinib $400 \mathrm{mg}$ in newly diagnosed chronic-phase chronic myeloid leukemia. Blood 120:3898-3905, 2012

29. Sasaki K, Strom SS, O'Brien S, et al: Relative survival in patients with chronic-phase chronic myeloid leukaemia in the tyrosine-kinase inhibitor era: Analysis of patient data from six prospective clinical trials. Lancet Haematol 2:e186-e193, 2015

30. Paquette $R$, Mauro M, Simonsson B, et al: Cardiovascular (CV)-related hospitalization in patients with chronic-phase chronic myeloid leukemia (CP-
CML) in SIMPLICITY, a prospective observational study. Haematologica 100:E1099, 2015 (abstr)

31. Pemmaraju N, Kantarjian HM, O'Brien $\mathrm{S}$, et al: Phase II clinical trial results of dasatinib for frontline therapy in patients with chronic myeloid leukemia (CML) in chronic phase (CP). Blood 124:4565, 2014 (abstr)

32. Hughes TP, Saglio G, Quintás-Cardama A et al: BCR-ABL1 mutation development during firstline treatment with dasatinib or imatinib for chronic myeloid leukemia in chronic phase. Leukemia 29: 1832-1838, 2015

33. Jabbour $E$, Kantarjian $H$, Jones $D$, et al: Frequency and clinical significance of BCR-ABL mutations in patients with chronic myeloid leukemia treated with imatinib mesylate. Leukemia 20: 1767-1773, 2006

34. Cohen MH, Williams G, Johnson JR, et al: Approval summary for imatinib mesylate capsules in the treatment of chronic myelogenous leukemia. Clin Cancer Res 8:935-942, 2002

35. Yilmaz M, Lahoti A, O'Brien S, et al: Estimated glomerular filtration rate changes in patients with chronic myeloid leukemia treated with tyrosine kinase inhibitors. Cancer 121:3894-3904, 2015

36. Shah NP, Wallis N, Farber HW, et al: Clinical features of pulmonary arterial hypertension in patients receiving dasatinib. Am J Hematol 90:1060-1064, 2015

37. Novartis: Tasigna (nilotinib) prescribing information. East Hanover, NJ, Novartis Pharmaceuticals Corporation, 2015

38. ARIAD: Iclusig (ponatinib) prescribing information. Cambridge, MA, ARIAD Pharmaceuticals, 2015

39. Quintás-Cardama A, Kantarjian H, O'Brien S et al: Pleural effusion in patients with chronic myelogenous leukemia treated with dasatinib after imatinib failure. J Clin Oncol 25:3908-3914, 2007

40. Saglio G, le Coutre $P$, Cortes J, et al: The observed and expected incidence of cardiovascular ischemic events in dasatinib-treated patients across a clinical trial program. Blood 124 4534, 2014 (abstr)

41. le Coutre PD, Hughes TP, Mahon F-X, et al: Low incidence of peripheral arterial disease in patients receiving dasatinib in clinical trials. Leukemia 10.1038/leu.2015.352 [epub ahead of print on December 21, 2015]

42. Eliasson L, Clifford S, Barber N, et al: Exploring chronic myeloid leukemia patients' reasons for not adhering to the oral anticancer drug imatinib as prescribed. Leuk Res 35:626-630, 2011

43. Marin D, Bazeos $A$, Mahon FX, et al: Adherence is the critical factor for achieving molecular responses in patients with chronic myeloid leukemia who achieve complete cytogenetic responses on imatinib. J Clin Oncol 28:2381-2388, 2010

44. Noens $L$, van Lierde MA, De Bock $R$, et al: Prevalence, determinants, and outcomes of nonadherence to imatinib therapy in patients with chronic myeloid leukemia: The ADAGIO study. Blood 113:5401-5411, 2009

45. Ibrahim AR, Eliasson L, Apperley JF, et al: Poor adherence is the main reason for loss of CCyR and imatinib failure for chronic myeloid leukemia patients on long-term therapy. Blood 117:3733-3736, 2011

46. Noens L, Hensen M, Kucmin-Bemelmans I, et al: Measurement of adherence to BCR-ABL inhibitor therapy in chronic myeloid leukemia: Current situation and future challenges. Haematologica 99: 437-447, 2014 


\section{AUTHORS' DISCLOSURES OF POTENTIAL CONFLICTS OF INTEREST}

Final 5-Year Study Results of DASISION: The Dasatinib Versus Imatinib Study in Treatment-Naïve Chronic Myeloid Leukemia Patients Trial

The following represents disclosure information provided by authors of this manuscript. All relationships are considered compensated. Relationships are self-held unless noted. I = Immediate Family Member, Inst = My Institution. Relationships may not relate to the subject matter of this manuscript. For more information about ASCO's conflict of interest policy, please refer to www.asco.org/rwc or jco.ascopubs.org/site/ifc.

\section{Jorge E. Cortes}

Consulting or Advisory Role: ARIAD, Bristol-Myers Squibb, Novartis, Pfizer

Research Funding: ARIAD (Inst), Bristol-Myers Squibb (Inst), Novartis (Inst), Pfizer (Inst), Teva (Inst)

\section{Giuseppe Saglio}

Consulting or Advisory Role: Bristol-Myers Squibb, Novartis, ARIAD, Pfizer

\section{Hagop M. Kantarjian}

Research Funding: Pfizer (Inst), ARIAD, Amgen (Inst), Bristol-Myers Squibb (Inst), Novartis (Inst)

Michele Baccarani

Honoraria: Bristol-Myers Squibb

Consulting or Advisory Role: Bristol-Myers Squibb

Speakers' Bureau: Bristol-Myers Squibb

\section{Jiř́i Mayer}

Consulting or Advisory Role: Novartis, Bristol-Myers Squibb

Research Funding: Novartis, Bristol-Myers Squibb

\section{Concepción Boqué}

Honoraria: Novartis, Bristol-Myers Squibb

Consulting or Advisory Role: Novartis

Travel, Accommodations, Expenses: Novartis, Bristol-Myers Squibb, Celgene

\section{Neil P. Shah}

Research Funding: Bristol-Myers Squibb, ARIAD, Pfizer, Daiichi Sankyo, Plexxikon

\section{Charles Chuah}

Honoraria: Bristol-Myers Squibb, Novartis

\section{Luis Casanova}

No relationship to disclose

Brigid Bradley-Garelik

Employment: Bristol-Myers Squibb

Stock or Other Ownership: Bristol-Myers Squibb

\section{George Manos}

Employment: Bristol-Myers Squibb

Stock or Other Ownership: Bristol-Myers Squibb

Andreas Hochhaus

Honoraria: Bristol-Myers Squibb, Novartis, Pfizer, ARIAD, Omniamed Consulting or Advisory Role: Novartis, Bristol-Myers Squibb, Pfizer, ARIAD

Research Funding: Novartis (Inst), Bristol-Myers Squibb (Inst), Pfizer (Inst), ARIAD (Inst), MSD

Travel, Accommodations, Expenses: Novartis, Bristol-Myers Squibb, Pfizer, ARIAD 


\section{Acknowledgment}

We thank all participating study sites for this analysis sponsored by Bristol-Myers Squibb. Professional medical writing and editorial assistance were funded by Bristol-Myers Squibb and provided by Samantha L. Dwyer, of StemScientific, an Ashfield Company, part of UDG Healthcare.

\section{Appendix}

\section{Methods}

Key exclusion criteria were as follows: serious, uncontrolled medical disorders or active infections; a corrected QT interval of more than 450 milliseconds; history of a serious bleeding disorder unrelated to chronic myeloid leukemia; previous or concurrent malignancy (excluding adequately treated basal or squamous cell skin cancer, cervical carcinoma in situ, or stage I or II cancer in remission, or patients with previous cancer who have been disease free for $\geq 3$ years); previous chemotherapy for peripheral stemcell mobilization; and pleural effusion at baseline.

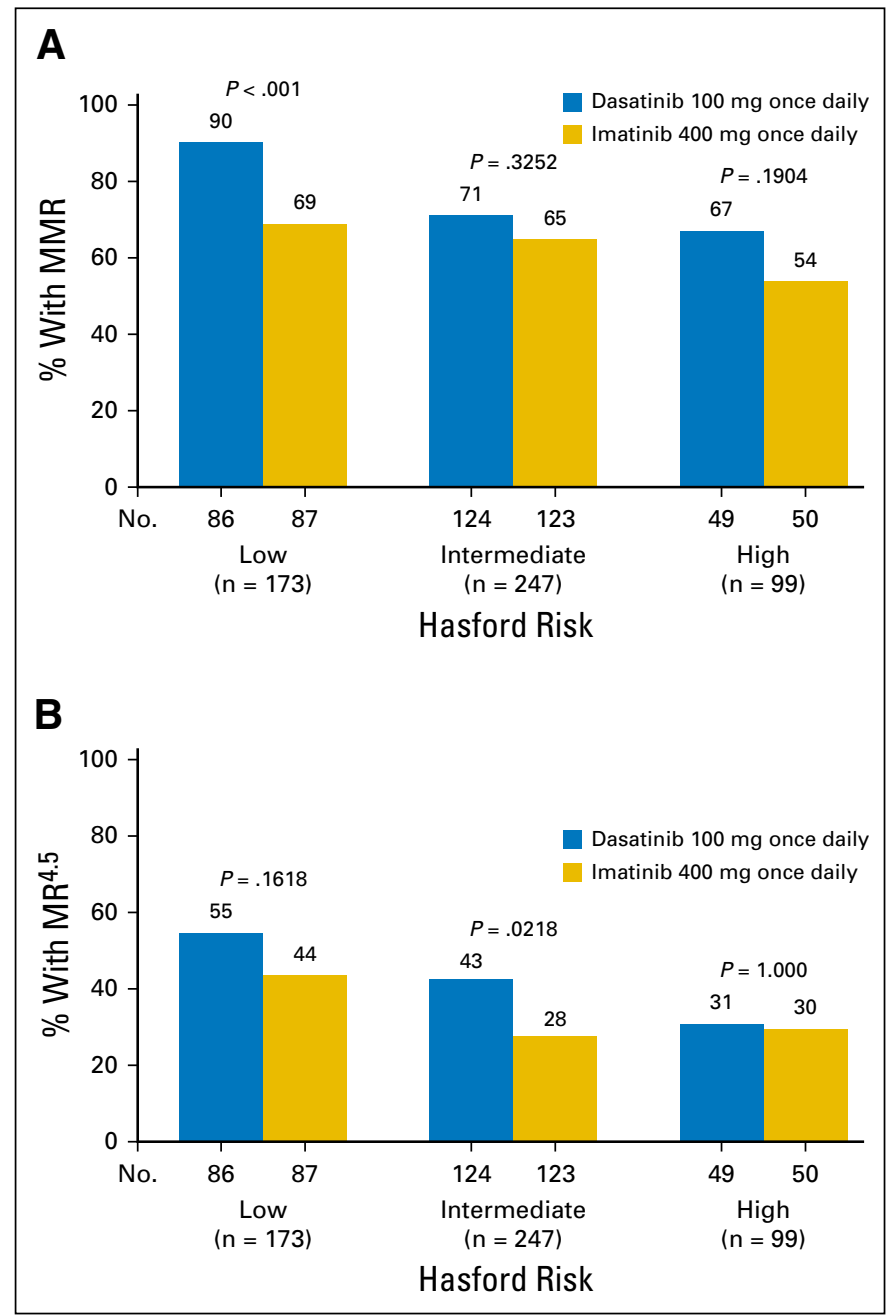

Fig A1. (A) Major molecular response (MMR) and (B) molecular response with a 4.5-log reduction in $B C R-A B L 1$ transcripts from baseline $\left(M^{4.5} ; B C R-A B L 1\right.$ transcript level $\leq 0.0032 \%$ [International Scale]) at any time by Euro (Hasford) risk score. 


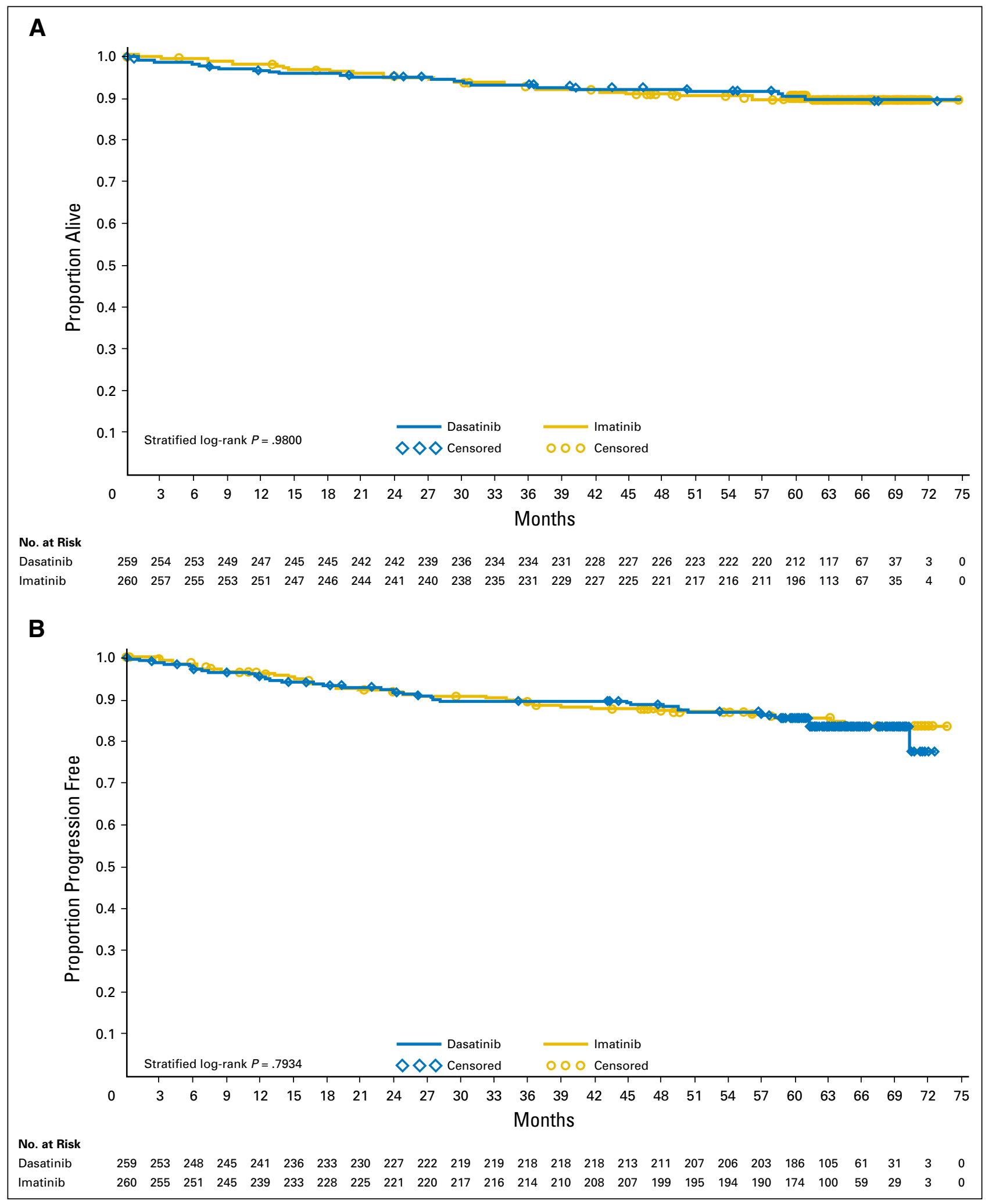

Fig A2. Kaplan-Meier curves for (A) overall survival and (B) progression-free survival in both treatment arms. A sensitivity analysis of progression-free survival was performed to include patients who discontinued treatment and experienced progression or died on treatment or during follow-up. 


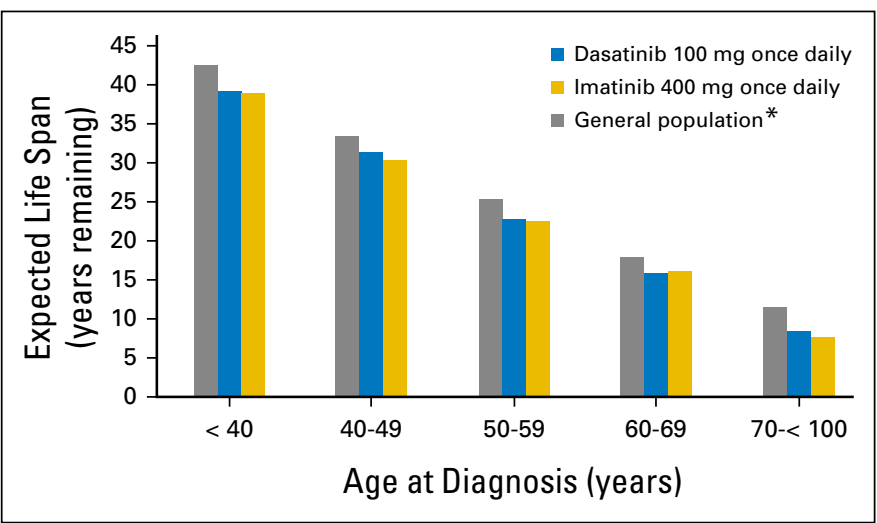

Fig A3. Expected survival by age at diagnosis for both treatment arms and a general population of patients without chronic myeloid leukemia. $\left(^{*}\right)$ Expected life span estimates were adapted from Ludwig et al. ${ }^{22}$ 
DASISION Final 5-Year Study Results

Table A1. AEs Leading to Treatment Discontinuation Regardless of Relationship to Study Treatment

$\mathrm{AE}$

No. of Patients (\%)

Patients* with any $\mathrm{AE} \dagger$ leading to discontinuation

Pleural effusion

Pulmonary hypertension

Blast phase in myelogenous leukemia

Thrombocytopenia

Dyspnea

Leukopenia

Acute myocardial infarction

Pericardial effusion

Chest pain

Diarrhea

Acute renal failure

Pleuritis

Pneumothorax

Pulmonary embolism

Lung adenocarcinoma

Transitional-cell carcinoma

Peripheral edema

Abdominal discomfort

Abdominal pain

Colitis

Pancreatic disorder

Bronchopneumonia

Infection

Meningoencephalitis, bacterial

Creatine phosphokinase increased

ECG OT prolonged

Diabetes mellitus

Renal failure

Optic neuritis

Blast cell proliferation

Neutropenia

Rash

Colon cancer

Nodal marginal zone B-cell lymphoma

Rectal carcinoma

Myocardial infarction

Asthenia

Performance status decreased

Alopecia

Erythema

Palmar-plantar erythrodysesthesia

Maculopapular rash

ALT increased

AST increased

Hypocalcemia

Hypophosphatemia

Cytogenetic abnormality

Toxic hepatitis

Dasatinib 100 mg Once Daily ( $\mathrm{n}=258$ )

Imatinib 400 mg Once Daily ( $n=258)$

$\begin{aligned} & 50(19) \\ & 15(6) \\ & 6(2) \\ & 3(1) \\ & 3(1) \\ & 2(1) \\ & 2(1) \\ & 2(1) \\ & 2(1) \\ & 2(1) \\ & 1(<1)\end{aligned}$

$1(<1)$

$1(<1)$

$1(<1)$

$1(<1)$

$1(<1)$

$1(<1)$

$1(<1)$

$1(<1)$

$1(<1)$

$1(<1)$

$1(<1)$

$1(<1)$

$1(<1)$

$1(<1)$

$1(<1)$

$1(<1)$

$1(<1)$

$1(<1)$

$1(<1)$

$1(<1)$

$26(10)$

$1(<1)$

0

3 (1)

2 (1)

0

0

0

0

0

$1(<1)$

$1(<1)$

0

0

0

0

0

0

0

0

0

0

0

0

0

0

0

0

0

0

0 2(1)

0 2(1)

$0+2(1)$

$0 \quad 1(<1)$

$1<1)$
$1(<1)$

$1(<1)$

$1(<1)$

$1(<1)$

$1(<1)$

$1(<1)$

$1(<1)$

$1(<1)$

$1(<1)$

$1(<1)$

$1(<1)$

$1(<1)$

$1(<1)$

$1(<1)$

$1(<1)$

Abbreviation: $A E$, adverse event.

* Patients may have had more than one AE.

tAEs listed were reported by investigators at the time of treatment discontinuation and were defined as any new untoward medical occurrence or worsening of a preexisting medical condition in a patient. AEs did not necessarily have a causal relationship with study treatment. 
Cortes et al

\begin{tabular}{|c|c|c|c|c|c|c|}
\hline \multirow[b]{2}{*}{ Mutation } & \multicolumn{3}{|c|}{ Dasatinib 100 mg Once Daily ( $\mathrm{n}=258$ ) } & \multicolumn{3}{|c|}{ Imatinib 400 mg Once Daily ( $n=258$ ) } \\
\hline & $\begin{array}{l}\text { Progression } \\
\quad(n=18)\end{array}$ & $\begin{array}{l}\text { Treatment Failure } \\
\qquad(\mathrm{n}=10)\end{array}$ & $\begin{array}{l}\text { Other* } \\
(n=219)\end{array}$ & $\begin{array}{l}\text { Progression } \\
\quad(n=23)\end{array}$ & $\begin{array}{l}\text { Treatment Failure } \\
\qquad(\mathrm{n}=14)\end{array}$ & $\begin{array}{l}\text { Othert } \\
(n=221)\end{array}$ \\
\hline Mutation analysis attempted, No. (\%) & $18(100)$ & $9(90)$ & $173(79)$ & $21(91)$ & $13(93)$ & $180(81)$ \\
\hline No. of patients with mutation(s)‡ & 10 & 3 & 2 & 10 & 4 & 5 \\
\hline \multicolumn{7}{|l|}{ Specific mutations, No. } \\
\hline M244V & 0 & 0 & 0 & 1 & 0 & 1 \\
\hline L248V & 0 & 0 & 0 & 0 & 1 & 0 \\
\hline Y253H & 0 & 0 & 0 & 0 & 1 & 0 \\
\hline V299L & 2 & 2 & 1 & 0 & 0 & 0 \\
\hline G250E & 0 & 0 & 0 & 0 & 1 & 2 \\
\hline E255KN & 0 & 0 & 0 & 1 & 1 & 0 \\
\hline D276G & 0 & 0 & 0 & 2 & 0 & 0 \\
\hline T315। & 6 & 1 & 1 & 0 & 0 & 0 \\
\hline F317I/L & 3 & 0 & 1 & 0 & 0 & 2 \\
\hline E355G & 0 & 0 & 0 & 1 & 1 & 0 \\
\hline L359C/IN & 0 & 0 & 0 & 4 & 0 & 0 \\
\hline L387M & 0 & 0 & 0 & 1 & 0 & 0 \\
\hline H396P/R & 0 & 0 & 0 & 1 & 0 & 1 \\
\hline E450G & 0 & 0 & 0 & 0 & 1 & 0 \\
\hline No mutation, No. & 8 & 5 & 24 & 11 & 8 & 37 \\
\hline No amplification,§ No. & 0 & 1 & 147 & 0 & 1 & 138 \\
\hline \multicolumn{7}{|c|}{ 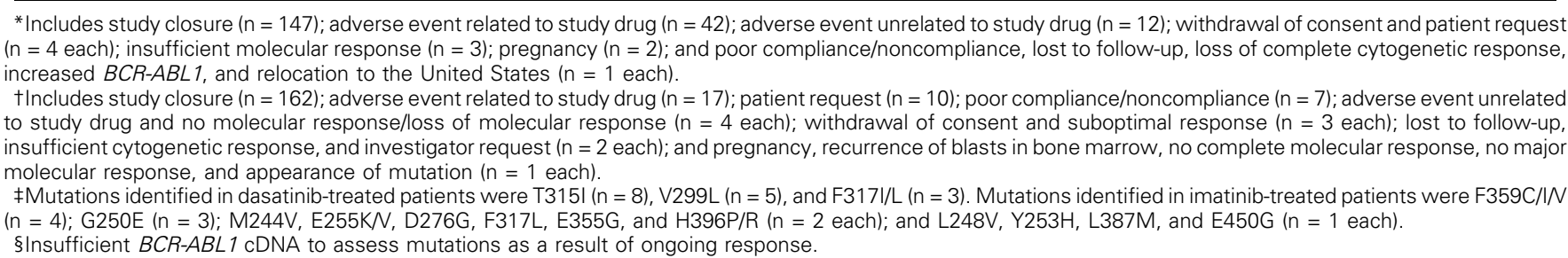 } \\
\hline
\end{tabular}

\begin{tabular}{|lcc|}
\hline \multicolumn{3}{|c|}{ Table A3. Incidence of PE in At-Risk Dasatinib-Treated Patients by the Year } \\
They Were Reported in the Study
\end{tabular}


DASISION Final 5-Year Study Results

Table A4. Any-Cause Arterial Ischemic Events

\begin{tabular}{|c|c|c|c|c|c|c|}
\hline \multirow[b]{3}{*}{ Event } & \multicolumn{6}{|c|}{ No. of Patients (\%) } \\
\hline & \multicolumn{3}{|c|}{ Dasatinib 100 mg Once Daily $(n=258$ ) } & \multicolumn{3}{|c|}{ Imatinib 400 mg Once Daily ( $n=258$ ) } \\
\hline & Any Grade & Grade 3 or 4 & Grade 5 & Any Grade & Grade 3 or 4 & Grade 5 \\
\hline Any ischemic event & $12(5)$ & $7(3)$ & $2(1)$ & $6(2)$ & $3(1)$ & $1(<1)$ \\
\hline CV event* & $10(4)$ & $5(2)$ & $2(1)$ & $4(2)$ & $2(1)$ & $1(<1)$ \\
\hline TIA & $2(1)$ & $2(1)$ & 0 & 0 & 0 & 0 \\
\hline PAD & 0 & 0 & 0 & $2(1)$ & $1(<1)$ & 0 \\
\hline
\end{tabular}

